\title{
International experience with secundum atrial septal defect occlusion by the buttoned device
}

\author{
P. Syamasundar Rao, MD, ${ }^{a}$ Eleftherios B. Sideris, MD, ${ }^{\text {b, }}$ Gerd Hausdorf, MD, ${ }^{d}$

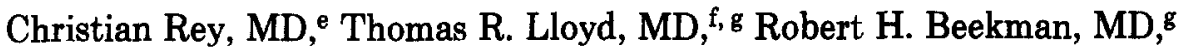 \\ Ann Marie Worms, MD, ${ }^{\mathrm{h}}$ Francois Bourlon, MD, ${ }^{\mathrm{i}}$ Eustaquio Onorato, MD, \\ Mohamed Khalilullah, MD, ${ }^{\mathrm{k}}$ and Jorge Haddad, $\mathrm{MD}^{\mathrm{l}}$ Madison, Wis., Athens, Greece, \\ Amarillo, Texas, Berlin, Germany, Lille and Nancy, France, Tucson, Ariz., \\ Ann Arbor, Mich., Monaco, Milan, Italy, New Delhi, India, and \\ Ribeirão Preto, Brazil
}

The incidence of congenital heart defects is $0.8 \%$ of liveborn infants. Of these, $8 \%$ to $13 \%$ are ostium secundum atrial septal defects, which can be successfully repaired by open heart surgical techniques with a low $(<1 \%)$ mortality rate. However, morbidity associated with cardiac surgery is universal, and residual scar is present in all. A less invasive method of repairing atrial septal defects, sparing patients the discomfort and morbidity of open heart surgery, would be advantageous if its mortality and complication rates were similar to or less than the surgical method. Pioneering works of King et al ${ }^{1-3}$ and Rashkind $^{4-6}$ have explored the potential of transcatheter methods of closure of atrial defects in replacing open heart surgery and have laid a foundation on which other transcatheter methods can be developed and refined. The initial devices used for atrial septal de-

From the a University of Wisconsin Medical School; the ${ }^{b}$ Athenian Institute of Pediatric Cardiology; 'Custom Medical Devices, Amarillo; ${ }^{\mathrm{d}}$ German

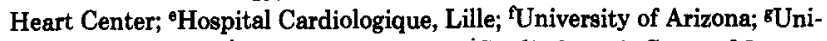

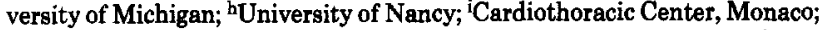
jsan Donato Milaneze, Milan; ${ }^{k}$ G. B. Pant Hospital, New Delhi; and 'Hospital do Coracao de Ribeiráo-Preto.

Supported in part by National Institutes of Health grants RR03186 and M01RR00042; a grand-in-aid from the Graduate School, University of Wisconsin, Madison; and a grant from the Oscar Rennebohm Foundation, Inc., Madison.

Received for publication March 4, 1994; accepted April 1, 1994.

Reprint requests: P. Syamasundar Rao, MD, Division of Pediatric Cardiology, H4/416 CSC, Cardinal Glennon Children's Hospital, $1465 \mathrm{~S}$. Grand Blvd., St. Louis, MO 63104.

AM HearT J 1994;128:1022-35.

Copyright $\odot 1994$ by Mosby-Year Book, Inc.

$0002-8703 / 94 / \$ 3.00+0 \quad 4 / 1 / 58111$ fect closure were modified by Rashkind ${ }^{6}$ and by Lock et al..$^{7}$ A different type of device was introduced by Sideris et al. ${ }^{8}$ The purpose of this communication is to present our international experience with the buttoned device in closing atrial septal defects and to evaluate the feasibility, safety, and effectiveness of this method of closure.

\section{METHODOLOGY}

After they gave informed consent, patients with secundum atrial septal defects were selected for transcatheter occlusion according to rules regulating custom-made devices in each country, including the United States. The study protocol for human use of the custom-made devices was approved by the Human Subjects Committee (Institutional Review Board) of each institution. Occlusions were performed at 16 institutions (Table I). Of the 180 transcatheter atrial septal defect occlusions performed during a 4.5-year period ending February 1993, 130 occlusions were performed under this protocol. The other 50 closures were performed at three U.S. institutions (University of Arizona, University of Michigan, and University of Wisconsin) under a Food and Drug Administration (FDA)-supervised clinical trial with investigational device exemption. The number of subjects at each institution varied between 2 and 25 patients.

Patient inclusion/exclusion criteria. Patients were selected on the basis of standard criteria established for selection of patients for surgical closure of atrial septal defects. ${ }^{9}$ Only patients with clinical and laboratory data, including echo-Doppler studies, suggest- 
Table I. Institutions and investigators participating in atrial septal defect occlusion clinical trial

1. Ali Sham's University Hospital, Cairo, Egypt (Ihab M. At tia, MD)

2. Athenian Institute of Pediatric Cardiology Athens, Greece; Custom Medical Devices, Amarillo, Texas (Eleftherios B. Sideris, MD)

3. Batra Hospital \& Medical Research Center, New Delhi, India (Rajeev Lochan, MD)

4. Cardiothoracic Center, Monaco (Francois Bourlon, MD)

5. Centre Chirurgical Mario-Lallelongue, Paris, France (Jean Losay, MD)

6. German Heart Center, Berlin, Germany (Gerd Hausdorf, MD)

7. Hospital do Coracão de Ribeirão Preto, Ribeirão Preto, Brazil (Jorge Haddad, MD)

8. Hospital Cardiologique, Lille Cédex, France (Christian Rey, MD)

9. G. B. Pant Hospital, New Delhi, India (Mohamed Khalilullah, MD)

10. San Donato Milaneze, Milan, Italy (Eustaquio Onorato, MD)

11. University of Arizona Hospitals, Tucson (Thomas R. Lloyd, MD)

12. University of Freiburg, Germany (R. Mocellin, MD)

13. University of Michigan Hospital, Ann Arbor (Robert $\mathbf{H}$. Beekman, MD)

14. University of Missouri Hospital, Columbia (Zudhi Lababidi, MD)

15. University of Nancy, Nancy, France (Ann Marie Worms, MD)

16. University of Wisconsin Hospital and Clinics, Madison (P. Syamasundar Rao, MD)

Table II. Modification of first-generation device

1. Strengthening and redesigning of "button loop." Instead of silk, $4 \mathrm{lb}$ proof nylon was used.

2. "Button" was made radiopaque by incorporating piece of Teflon-coated wire within "button."

3. Loading system was strengthened by replacing double thread in loading wire with $4 \mathrm{lb}$ proof nylon.

4. Thinner $1 / 6$-inch foam replaced $1 / 8$-inch polyurethane foam

ing the need for surgical correction were chosen. Two-dimensional echocardiographic views of the atrial septum in multiple views (Fig. 1) were obtained to evaluate for presence of septal margins adequate to support the device. Assessment of adequacy of the septal rims is arbitrary and is at the discretion of the investigators at each of the institutions. At the time of cardiac catheterization, patients with a pulmonary-to-systemic flow ratio of $<1.5$ were excluded. Stretched diameter of the atrial septal defect was measured by balloon occlusion ${ }^{10-13}$ in each case; patients with stretched diameter $>25 \mathrm{~mm}$ were also excluded. Twelve adult patients with cerebrovascular accidents caused by presumed paradoxic embolism
Table III. Protocol for transcatheter occlusion of atrial septal defects with buttoned device

1. Premedication with sedative mixture. General anesthesia was used in 18 patients in whom transesophageal echocardiographic monitoring was used.

2. Complete cardiac catheterization via percutaneous femoral venous route: $(A)$ to exclude other cardiac defects, $(B)$ to determine location of defect, and $(\mathrm{C})$ to probe all pulmonary veins from left atrium.

3. Balloon sizing of atrial septal defect. ${ }^{10-13}$

4. Selection of device 15 to $20 \mathrm{~mm}$ larger than stretched atrial defect diameter; table of device sizes (Table V), developed on basis of concepts detailed elsewhere ${ }^{14}$ served as guide in device selection.

5. Placement of femoral arterial line for monitoring systemic pressure during procedure.

6. Heparin $100 \mathrm{U} / \mathrm{kg}$, maximum 3000 Units, intravenously.

7. Femoral venous catheter/sheath was replaced with long $8 \mathrm{~F}$ sheath (Cordis Corp., Miami, Fla.). For 45 and $50 \mathrm{~mm}$ devices, $9 \mathrm{~F}$ sheath was used. Tip of sheath was positioned in mid left atrium.

8. Occluder component of device was folded and introduced into sheath. An $8 \mathrm{~F}$ end-hole catheter (pusher) was inserted over loading wire into sheath and advanced, pushing occluder toward left atrium. Occluder was delivered into left atrium under fluoroscopic (Fig. 10) and/or echocardiographic (Fig. 3) guidance. Occluder springs open and assumes its original shape. Occluder was aligned with atrial septum, and care was taken to avoid other structures.

9. Pusher catheter was removed. Counteroccluder was threaded over loading wire (through rubber piece, buttonhole) and positioned within sheath. Pusher catheter was reintroduced, and counteroccluder was delivered into right atrium.

10. Introduction of $1 \mathrm{~mm}$ knot of occluder (button) through rubber piece (buttonhole) of counter-occluder is performed by simultaneously gently pulling occluder against atrial septum and advancing counteroccluder with tip of long sheath. Verification that knot has been pulled through buttonhole was obtained by fluoroscopy with aid of radiopaque marked on knot. Radiopaque wire of counteroccluder was positioned past radiopaque button (Fig. $10, C$ and $D$ ). Verification of atrial septal defect occlusion was assessed by echo Doppler studies (Fig. 5).

11. Loading wire was cut at tip and withdrawn, leaving two nylon strands holding device. Device was disconnected by pulling one of two nylon strands, thus disconnecting implanted device from loading system. During both maneuvers, tip of sheath was gently pressed against device to prevent application of excessive force on device, thereby preventing inadvertent dislodgment of device.

12. Fifteen minutes after device implantation, blood samples for measuring oxygen saturations from main pulmonary artery, superior vena cava, and femoral artery were obtained, and main pulmonary artery cineangiogram was performed, in 80 of 180 patients.

13. Three doses of Cefazolin ( $50 \mathrm{mg} / \mathrm{kg} /$ day) were administered to all subjects; first dose was given intravenously in catheterization laboratory, second and third doses were given 6 and 12 hours after first dose.

14. Aspirin $5-10 \mathrm{mg} / \mathrm{kg} /$ day by mouth was given starting day after device implantation. Aspirin was discontinued 6 to 12 weeks later. 


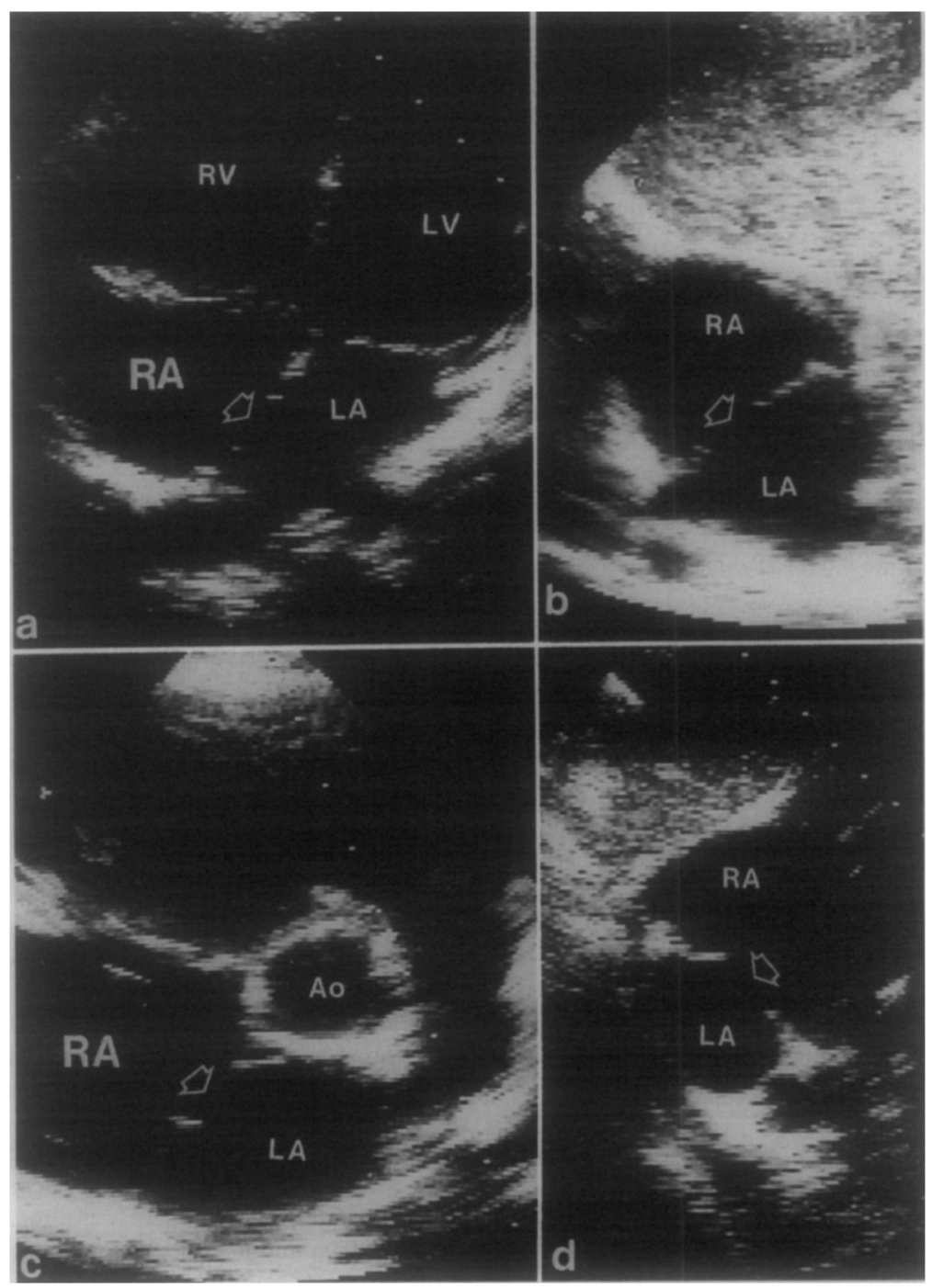

Fig. 1. Selected video frames of two-dimensional echographic images of atrial septum in multiple views to demonstrate atrial septal rim. a, Apical, four-chamber; b, subcostal, long-axis; c, precordial, short-axis; and d, subcostal, short-axis views are shown. Arrows, Atrial septal defect. Note good-sized margins in each view. Patient is good candidate for transcatheter closure. Ao, Aortic; $L A$, left atrium; $L V$, left ventricle; $R A$, right atrium; $R V$ right ventricle.

via an atrial septal defect or patent foramen ovale were included, irrespective of the level of shunt.

The device. The device (Fig. 2) consists of three components, an occluder, a counter occluder, and a delivery system, and has been described previously. ${ }^{8,14-16}$ Modifications of the first-generation device are listed in Table II, and changes in the second-generation device are shown in Fig. 2.

Device implantation. The procedure of device implantation across the atrial septum is detailed in our previous reports, ${ }^{14-17}$ outlined in Table III, and shown in Fig. 3.

Follow-up. Clinical evaluation, chest roentgeno- gram, and echo Doppler studies were performed 1 day and 1,6, and 12 months after the occlusion and yearly thereafter. Clinical evaluation focused on symptoms and physical findings of a residual atrial septal defect. Chest roentgenograms were examined for device displacement and wire fractures. Echo Doppler studies were used to assess right ventricular volume overload (as defined in Table IV), position of device, and residual shunts. Shunts were quantitated, as outlined in Table IV. Additional abnormalities, if any, were also recorded.

Data analysis. Data are expressed as mean $\pm \mathrm{SD}$ for continuous, normally distributed variables. Median 
2nd Generation Device

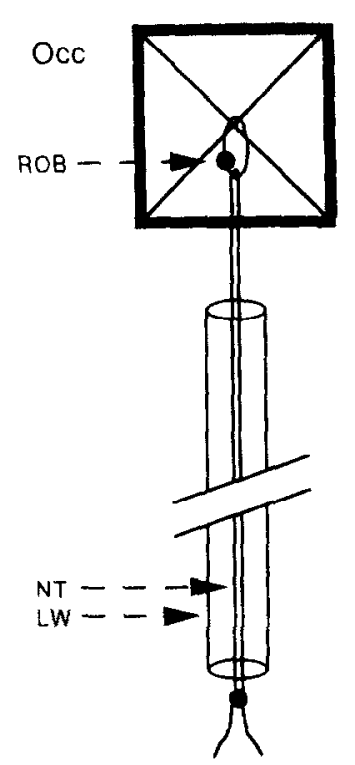

3rd Generation Device

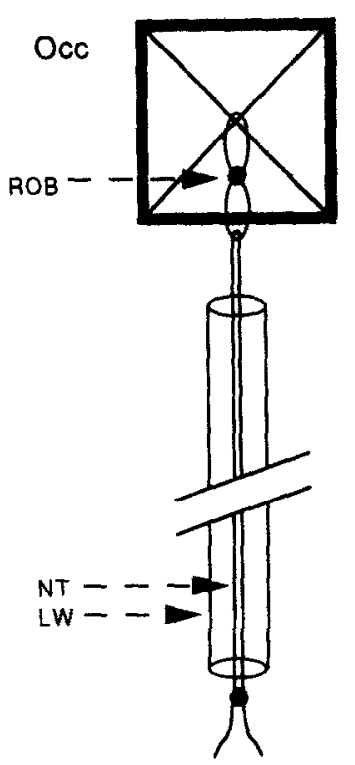

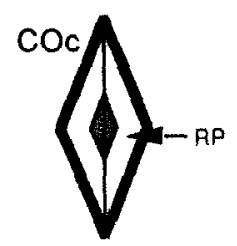

Fig. 2. Second- and third-generation buttoned devices. Second-generation device consists of occluder $(\mathrm{Occ})$ and counteroccluder $(\mathrm{COc})$. Occ is composed of $\mathrm{x}$-shaped wire skeleton covered with $1 / 6$-inch polyurethane foam. A $2 \mathrm{~mm}$ string loop is attached to center of occluder. Loop is closed with knot made radiopaque. This radiopaque button $(R O B)$ can easily be visualized on fluoroscopy. Folded 0.008 inch nylon tread $(N T)$ is passed through hollow loading wire $(L W)$ after having passed through loop in center of occluder. Counter-occluder consists of single-strand, Teflon-coated, wire skeleton covered with rhomboid-shaped polyurethane foam with rubber piece $(R P)$ sutured in its center. Third-generation device modification is introduction of additional loop immediately below radiopaque button. This will convert eccentric button of second-generation device to be aligned straight, thus making it easier to button occluder and counteroccluder across atrial septum.

values and ranges are given for data with skewed distribution. Comparisons between preocclusion and postocclusion values were made by two-tailed, paired $t$ test, and comparisons between groups were performed by analysis of variance. Categoric variables were compared by using chi-squared tests (for example, Fisher exact and McNemar's). When multiple comparisons were made, the Bonferroni correction was applied. Actuarial analysis of event-free rates and rates of resolution of residual shunts were carried out by means of the Kaplan-Meier method. The level of statistical significance was set at $p<0.05$.

\section{OBSERVATIONS}

Patients. During a 4.5-year period ending February 1993,200 patients underwent cardiac catheterization to confirm the clinical diagnosis, to balloon-size $\mathrm{e}^{10-13}$ the atrial septal defect, and to consider transcatheter occlusion. Occlusion was not attempted in 10 patients either because of a small (pulmonary-to-systemic flow ratio $<1.5: 1$ ) shunt ( 1 patient) or because of a large (stretched diameter $>25 \mathrm{~mm}$ ) defect ( 9 patients; Fig. 4). In seven other patients, the occluder component was delivered into the left atrium, but the occluder was pulled through the defect (either inadvertently or because of a presumably large defect). The devices were retrieved via the venous sheath in six patients or by femoral vein cut-down in two patients. In three patients the device was buttoned across the atrial septum but, the investigator believed the device to be unstable or to have caused an increase in right-to-left shunt; therefore the device was withdrawn and retrieved out of the patient (1 via the sheath, 1 by femoral venous cut-down, and 1 by surgery). The remaining $180(90 \%)$ patients underwent transcatheter occlusion. The patients' ages ranged between 0.6 years and 76 years, with a median age of 7 years, with 61 children below $<5$ years and 36 adults $>20$ years. The weight of these patients ranged between 3.6 and $105 \mathrm{~kg}$, with a median of 22 $\mathrm{kg}$. Fifteen of the 180 patients have previously been reported. ${ }^{14-17}$ Fifty occlusions monitored by the FDA in three U.S. centers ${ }^{18}$ are also included in this report.

Size of the atrial septal defect. The atrial septal defect was measured in the subcostal views ${ }^{12,13}$ during the echo Doppler study before transcatheter occlu- 


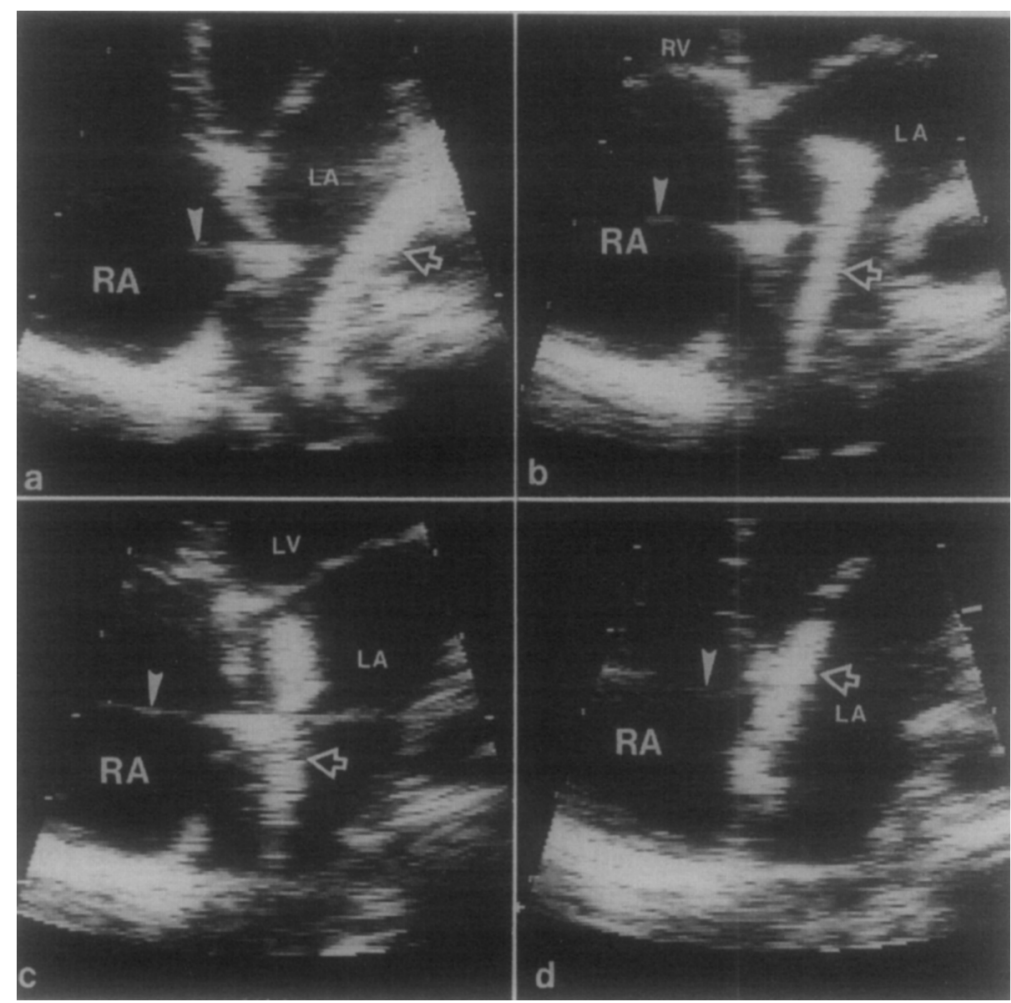

Fig. 3. Selected video frames of apical four-chamber two-dimensional views of atrial septum during device implantation. Occluder is shown after its release in left atrium (LA) (open arrows) in a-d as it is slowly withdrawn toward atrial septum. Solid arrowhead, Loading wire; $L V$, left ventricle; $R A$, right atrium; $R V$, right ventricle.

sion. The echographic size of the atrial septal defect was $10.6 \pm 3.8 \mathrm{~mm}$, with a range of 5 to $24 \mathrm{~mm}$. In the patients with left-to-right shunting across the atrial septal defect $(n=168)$, the pulmonary-to-systemic flow ratio was $2.1 \pm 0.6$; the range was 1.5 to 3.8 . Stretched diameter measured by balloon-sizing is generally larger than the echocardiographic measurement ${ }^{12,13}$ and was $15.8 \pm 4.6 \mathrm{~mm}$, with a range of 5 to $25 \mathrm{~mm}$.

Device implantation. Successful implantation of the device across the atrial septal defect was accomplished in 166 (92\%) of 180 patients in whom the device was released or $166(83 \%)$ of 200 patients taken to catheterization laboratory with the intent to occlude the defect (Fig. 4). The outcome of the unsuccessful implantations will be described later. The first-generation device was used in the initial 9 patients. The modified (Table II and Fig. 2), secondgeneration device was used in 106 patients, and a third-generation device with an additional loop (Fig. 2) was used in the remaining 65 patients. The size of the devices used varied between 25 and $50 \mathrm{~mm}: 25$ mm devices were used in 10 patients; $30 \mathrm{~mm}$ in $31 ; 35$ $\mathrm{mm}$ in $50 ; 40 \mathrm{~mm}$ in $52 ; 45 \mathrm{~mm}$ in $19 ; 50 \mathrm{~mm}$ in 13 , and miscellaneous sizes in the remaining 5 . An $8 \mathrm{~F}$ sheath was used for delivery of 148 of the devices and a $9 \mathrm{~F}$ sheath for the remaining 32 devices.

Immediate results. In 166 of 180 implantations, the atrial defects were effectively occluded as demonstrated by (1) decrease in pulmonary-to-systemic flow ratio by oximetry from $2.1 \pm 0.6$ to $1.05 \pm 0.1$ $(p<0.01)$ in 80 patients in whom such data were available; (2) normalized $\mathrm{S}_{2}$ and disappearance of middiastolic murmur by auscultation $(n=166)$; and (3) improvement in right ventricular volume overloading by echocardiogram $(n=166)$.

Oxygen saturation data obtained after device implantation was available in 80 patients; the pulmonary-to-systemic flow ratio was 1.0 in all but 12 patients. Those 12 had a pulmonary-to-systemic flow ratio of $1.3 \pm 0.2$, with a range of 1.1 to 1.7 ; median was 1.2. Levophase of the pulmonary artery cineangiogram was evaluated in all these 80 patients. Small atrial shunts were observed in only 12 patients, the same patients with demonstrable shunt by oximetry.

Echo Doppler studies performed after device implantation in all patients in whom the implant was successful revealed a well-positioned device across 
Table IV. Grading of atrial shunt by echo Doppler studies

\begin{tabular}{|c|c|}
\hline Grade & Criteria \\
\hline \multirow[t]{3}{*}{ None } & $\begin{array}{l}\text { No defect by two-dimensional } \\
\text { echo }\end{array}$ \\
\hline & $\begin{array}{l}\text { No color Doppler disturbance } \\
\text { on right atrial side of device }\end{array}$ \\
\hline & No RV volume overload* \\
\hline \multirow[t]{3}{*}{ Trivial } & $\begin{array}{l}\text { No defect by two-dimensional } \\
\text { echo }\end{array}$ \\
\hline & $\begin{array}{l}\text { Minimal color disturbance on } \\
\text { right atrial side of device }(<1 \\
\text { mm width at origin of color } \\
\text { Doppler jet) }\end{array}$ \\
\hline & No RV volume overload* \\
\hline \multirow[t]{3}{*}{ Small } & $\begin{array}{l}\text { No defect by two-dimensional } \\
\text { echo }\end{array}$ \\
\hline & $\begin{array}{l}1 \text { to } 2 \mathrm{~mm} \text { width of color Dop- } \\
\text { pler jet, either in center or on } \\
\text { periphery of device }\end{array}$ \\
\hline & No RV volume overload* \\
\hline \multirow[t]{3}{*}{ Moderate } & $\begin{array}{l}\text { Defect visualized on two-dimen- } \\
\text { sional echo }\end{array}$ \\
\hline & $>2 \mathrm{~mm}$ width of color jet \\
\hline & $\begin{array}{l}\text { RV volume overload* may be } \\
\text { present }\end{array}$ \\
\hline \multirow[t]{3}{*}{ Large } & $\begin{array}{l}\text { Defect visualized by two-dimen- } \\
\text { sional echo }\end{array}$ \\
\hline & $\begin{array}{l}\text { Large and/or multiple color } \\
\text { Doppler jets }\end{array}$ \\
\hline & RV volume overload* \\
\hline
\end{tabular}

$R V$, Right ventricle

* RV volume overload is defined as enlarged RV (>95th percentile for patient's body surface area) and flat to paradoxic interventricular septal motion.

the atrial septal defect (Fig. 5). In $92(55 \%)$ patients ( $n=168$; 166 successful implantations plus 2 unbuttonings that occurred later) no residual shunts were observed (Fig. 5). In the remaining $76(45 \%)$ patients, 62 trivial, 11 small, and 3 moderate shunts could be detected by color Doppler flow studies (Table IV). When effective occlusion (by echo Doppler criteria) is defined as trivial or no residual shunt along with resolution of right ventricular volume overload, 154 $(92 \%)$ of 168 had effective occlusions.

Complications. Significant complications include unbuttoning, whole-device embolization, and atrial perforation. Unbuttoning was the most common complication and occurred in $13(7.2 \%)$ of cases. Whole-device embolization occurred once $(0.6 \%)$. Ten of these 14 events occurred while the patients were in the catheterization laboratory; in the other 4 , device dislodgment was discovered 4 hours, 24 hours, 1 week, and 4 weeks later, respectively. The patients remained hemodynamically stable. Transcatheter retrieval of the device was accomplished in four patients, who underwent elective surgical correction of

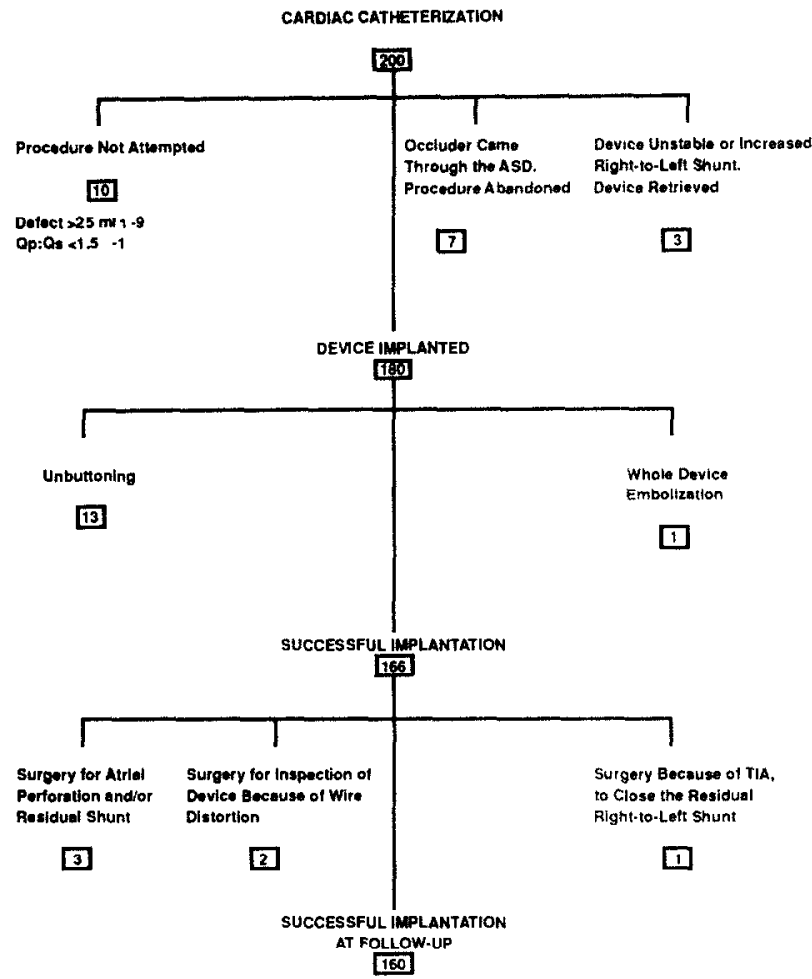

Fig. 4. Flow chart of patients taken to catheterization laboratory with intent to close atrial septal defect ( $A S D$ ). $Q p: Q s$, Pulmonary-to-systemic flow ratio; TIA, transient ischemic attack.

their atrial septal defect at a later date. Surgical closure of the atrial defect, along with extraction of the dislodged device, was performed in the remaining 10 patients. Nine of these devices (occluders) were in the left atrium, and their retrieval did not add to the operation. Pulmonary arteriotomy was required in one patient with whole-device embolization into the main pulmonary artery. Eight counteroccluders were embolized into the pulmonary artery and five into the right atrium. Seven of the 13 were retrieved at surgery, 4 transvenously, and 2 were left alone because they were not obstructive by pressures and angiography. There were no deaths. Three of the 14 device dislodgements have been mentioned in previous publications. . $^{14,16,19}$

Twelve of the 13 device unbuttonings occurred during the initial experience of the investigators, indicating a learning curve. When initial experience is defined as the first 10 cases for each investigator, 12 $(9.9 \%)$ unbuttonings were found among 121 patients. This is higher than that seen with investigators having greater experience ( $\geq 10$ cases) in device implantation, that is, $1(1.7 \%)$ in $59(p=0.06)$, although this did not attain preset statistical significance. Simi- 


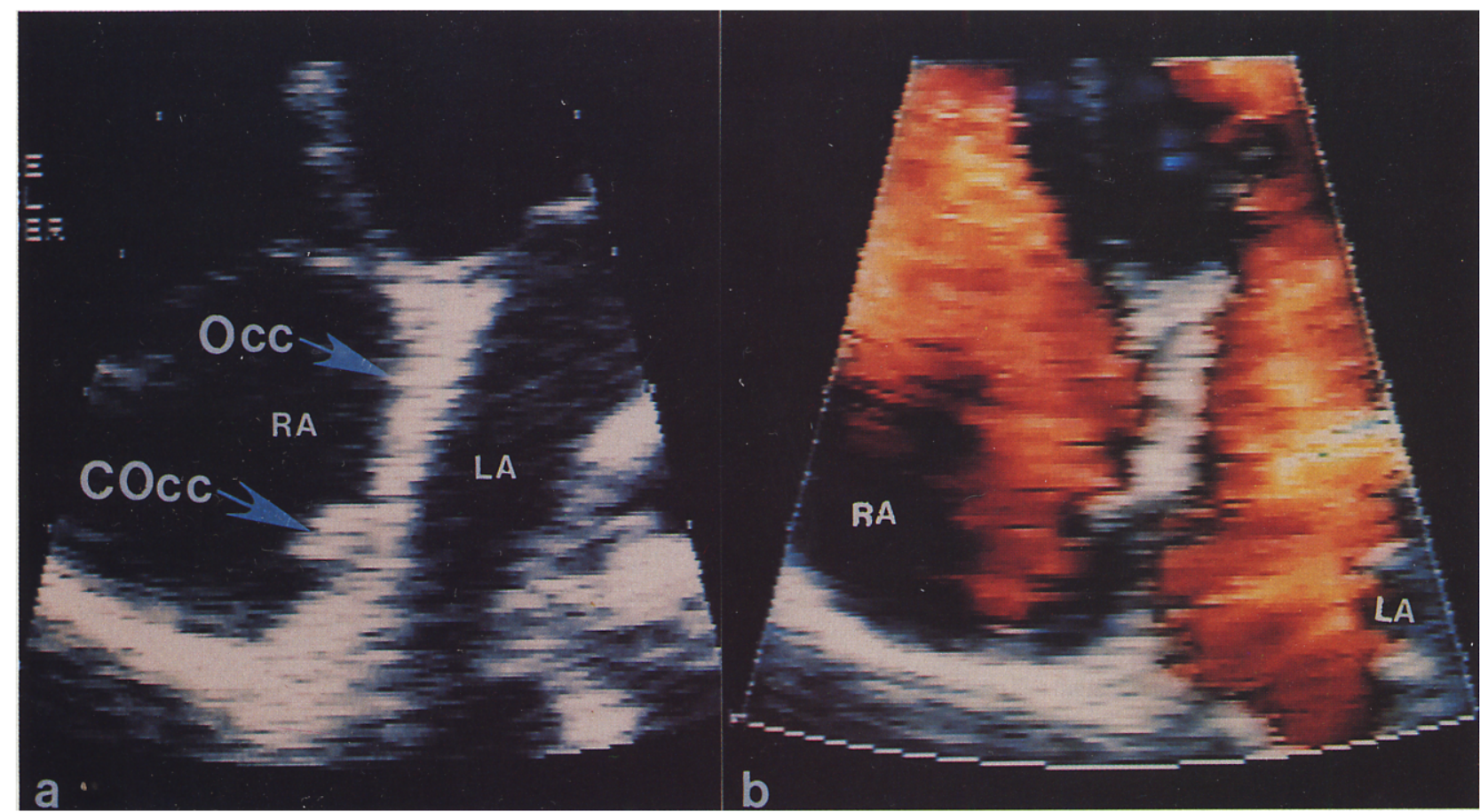

Fig. 5. Two-dimensional and color Doppler images of atrial septum obtained from apical view immediately after device implantation. Note good position of occluder (Occ) and counter occluder (COcc) (on end) across atrial septum (a). There was no evidence for shunt by color Doppler (b). $L A$, Left atrium; $R A$, right atrium.

larly, the influence of improvement with successive generations of the device on the prevalence of unbuttonings is examined in Fig. 6. There is no significant difference $(p=0.99)$ in the prevalence of unbuttoning between first and second generations of the devices. There is an apparent decrease in unbuttoning after the introduction of the third-generation device, but this also did not attain statistical significance $(p=0.135)$.

Atrial perforation occurred twice, both times related to rough manipulation of the device by new investigators. In one case there was chest pain and evidence for small hemopericardium by echocardiography. The patient was operated on electively 1 month later. In the second patient, the atrial perforation was not clinically evident and was an incidental finding during surgery for device malposition and residual shunt.

Minor complications included transient arrhythmias (atrial extrasystoles, sinus tachycardia, and atrial fibrillation in one adult patient) and trivial mitral $(n=3)$ or tricuspid $(n=2)$ insufficiency detected by color Doppler echocardiography. In two of our patients, atrioventricular valve insufficiency may be related to close proximity of a device arm to valve leaflets. Right-sided entry of air bubbles (microcavitations) was seen by echocardiography during device implantation in a few cases. In one patient there was significant air entry into the right heart with a transient drop in blood pressure. There were, however, no neurologic sequelae.

Follow-up. Follow-up clinical, chest $\mathrm{x}$-ray, and echo Doppler studies are available in all patients in whom successful device implantation has been accomplished. The follow-up duration varied between 1 month and 4 years, with a median of 12 months. Follow-up was available at 1,6 , and 12 months after device implantation in 164,141, and 107 patients, respectively. Very few patients had follow-up data longer than 1 year after implantation; therefore follow-up results beyond 1 year were excluded from further analysis. Clinical, chest $\mathrm{x}$-ray, and echo Doppler data were available in each patient at each follow-up interval indicated. In two patients devices were explanted and atrial defects closed because of significant residual shunts 3 and 9 months after implantation, respectively. Because of reports of breakage of wire hinges at follow-up after implantation of the Bard Clamshell Septal Umbrella (USCI, Billerica, Mass.), ${ }^{20,21}$ we specifically examined the chest 


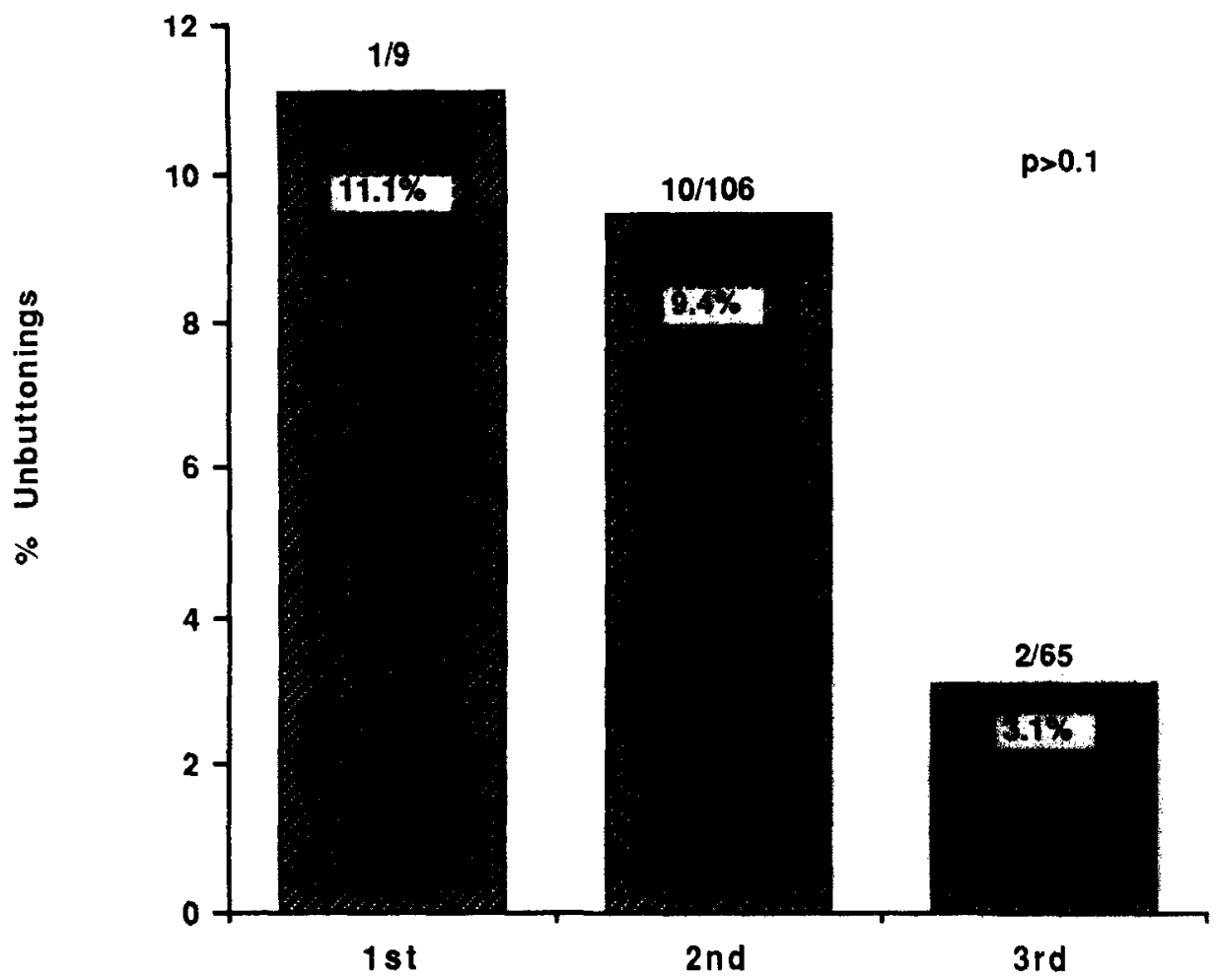

Fig. 6. Prevalence of unbuttonings with each generation of device during its evolution. Note that there is no significant $(p=0.99)$ difference between first- and second-generation devices. Although prevalence of unbuttonings appears to be less with third-generation device, this difference did not attain statistical significance $(p=0.135)$.

roentgenograms for this complication. No wire fractures or migration of the radiopaque device components were observed except in two patients in whom wire distortion was noted at the 6-month follow-up visit. In one of these the core wire was embolized into the axillary artery and was extracted via a small incision with the patient under local anesthesia. At the discretion of the primary cardiologists caring for these two patients, surgery was performed. In both patients the device was found to be completely endothelialized; the surgeon removed the wires and left the device in place. These two patients had the device implanted in the fall of 1992 from a single batch of devices manufactured in the fall of 1992 . The problem was traced to a defective processing technique that has been rectified without recurrence of the problem. Actuarial event-free (surgical intervention for atrial perforation or removal or inspection of the device with or without closure of the atrial defect is considered an event) rates are shown in Fig. 7. In the remaining patients there were no residual murmurs indicative of an atrial septal defect, and the second heart sound was normal. M-mode echographic images suggested continued disappearance of volume overloading and decrease in the size of the right ventricle. Two-dimensional echocardiography revealed stable position of the device. Color flowmapping studies showed a tendency for the residual shunts to become smaller and disappear. There was a reduction of small shunts to trivial and trivial to no shunts. The incidence and magnitude of residual shunts are shown in Fig. 8. There is a gradual increase in the percentage of subjects without residual shunts, and the magnitude and prevalence of residual shunts gradually decreased with increasing follow-up duration. Although there was no statistically significant difference between day 1 and 1-month follow-up $(p=0.62)$, there was a significant decrease in the prevalence of residual shunt 6 months $(p=0.003)$ and 12 months $(p<0.001)$ after device implantation (Fig. 8). Rates of resolution of residual shunts present immediately after device placement are shown in Fig. 9. Fifteen unselected patients with trivial shunts by color Doppler studies underwent cardiac catheterization 6 to 12 months after device implantation. No shunts were demonstrated by oximetry in 12 patients. In three patients shunts were small, with a pulmonary-to-systemic flow ratio of 1.1 to 1.2 . 


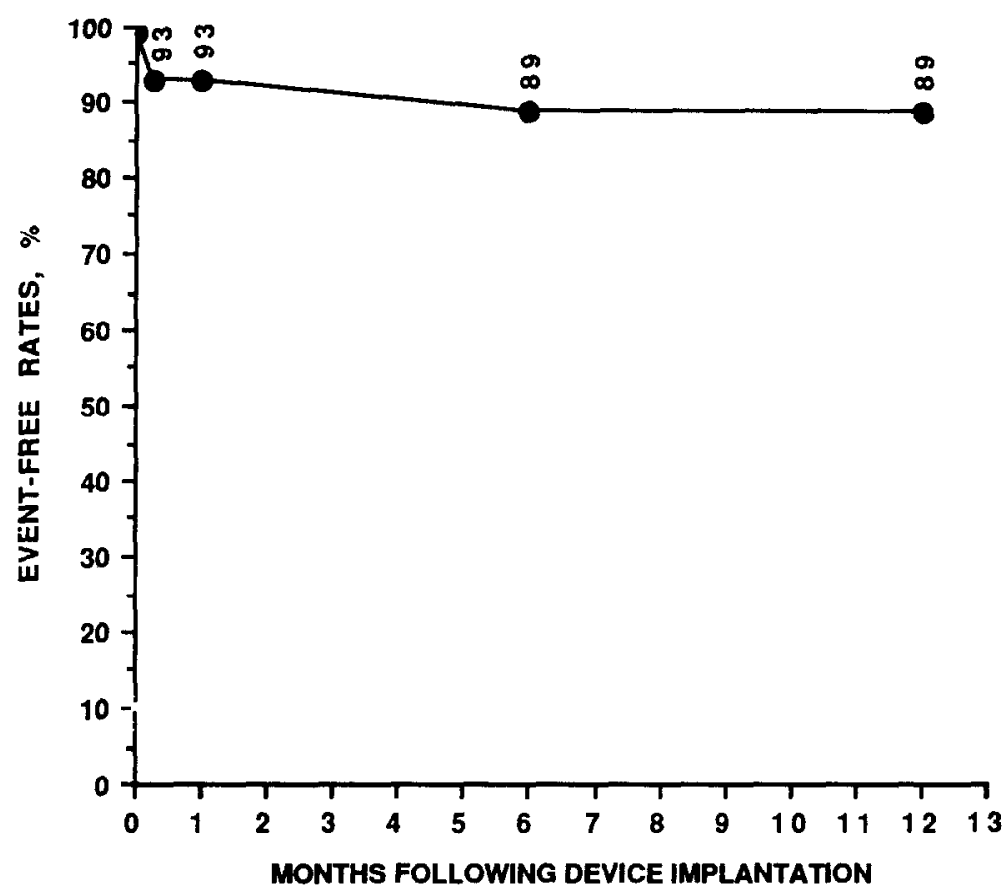

Fig. 7. Graph shows actuarial event-free rates after transcatheter occlusion of secundum atrial septal defect with buttoned devices.

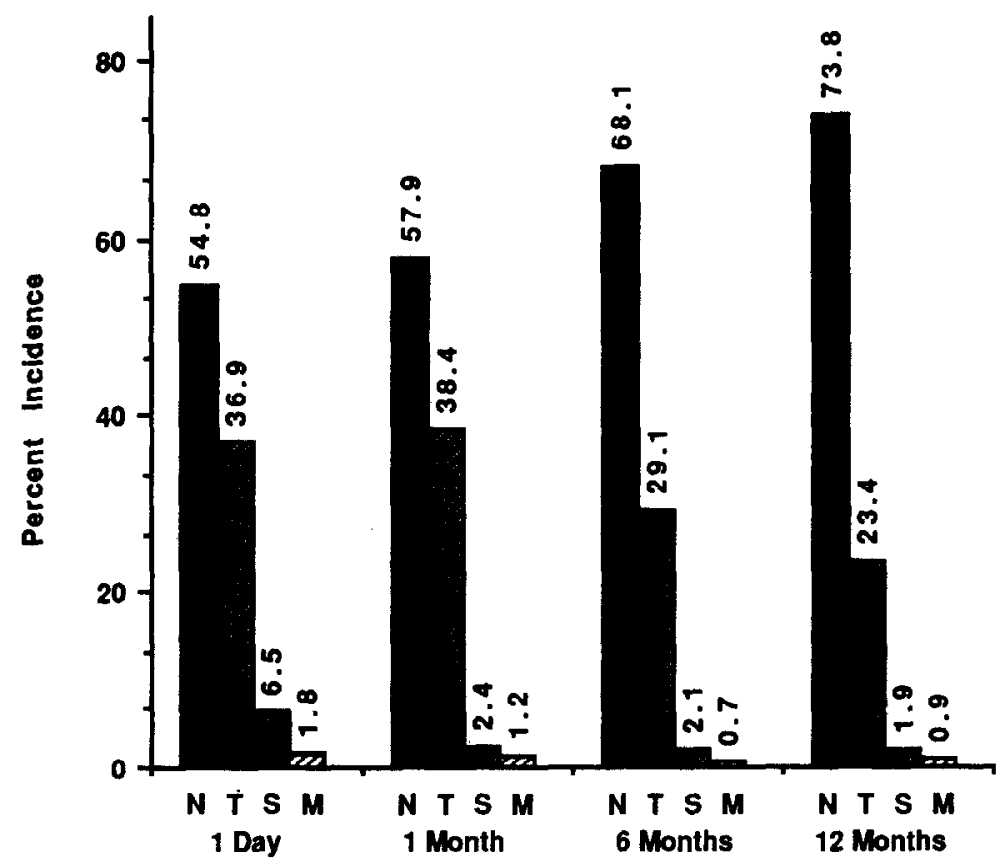

Fig. 8. Incidence of residual shunts after transcatheter occlusion of secundum atrial septal defects. McNemar's test for pairwise comparisons of data was used. To adjust for multiple comparisons, $0.05 / 3=0.017$ was used as level of significance for each comparison. There was no significant difference $(p=0.62)$ between 1 day and 1 month. However, there was significant reduction in residual shunt at 6 months $(p=0.003)$ and 12 months $(p<0.001)$ after device implantation when compared to those at 1 day after implantation. $N$, No shunt; $T$, trivial shunt; $S$, small shunt; $M$, moderate shunt. 


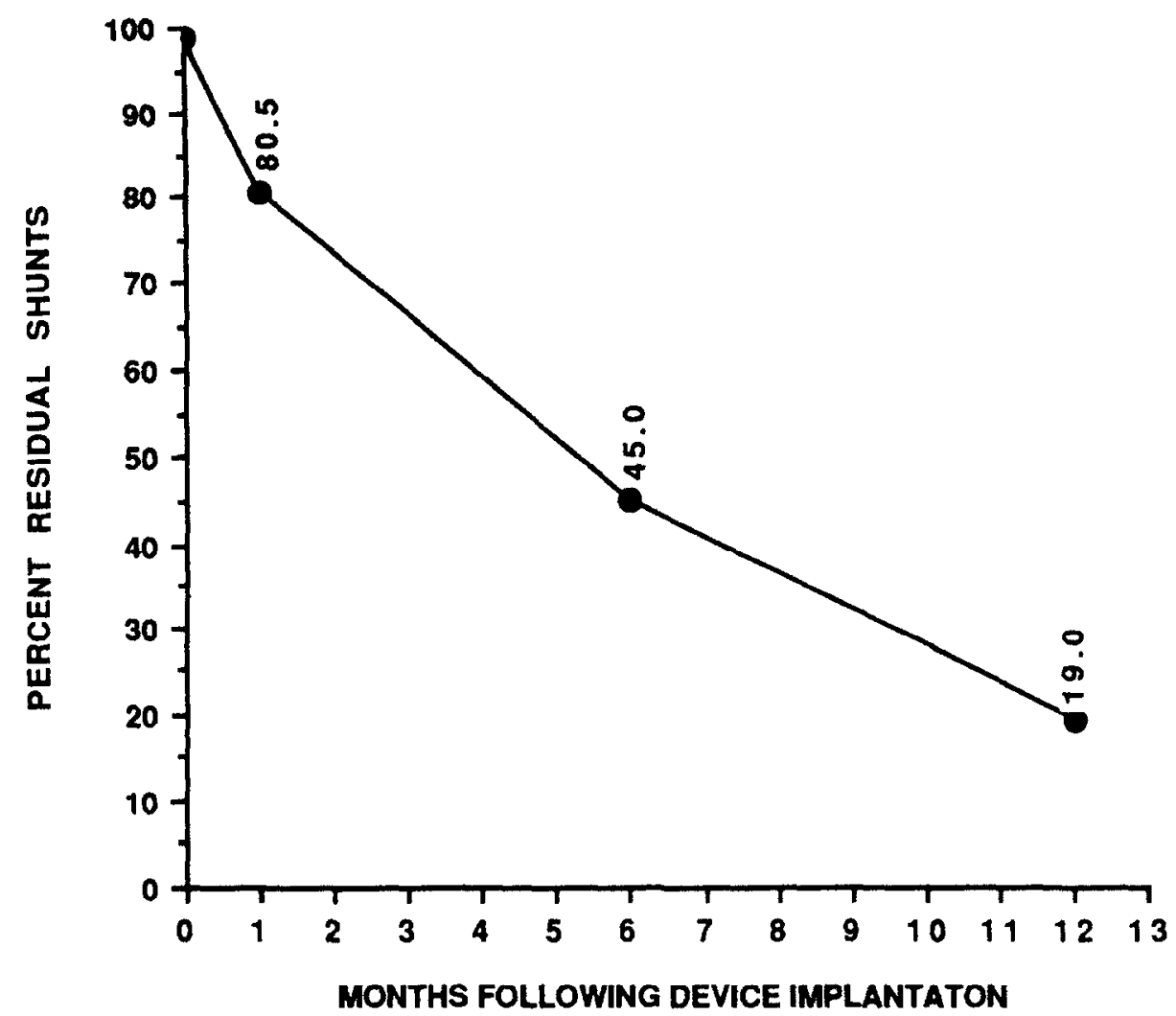

Fig. 9. Actuarial resolution of residual shunts for patients who had shunts 1 day after device placement.

No recurrence of paradoxic embolism was observed in the 11 of 12 patients in whom the atrial defect was closed to prevent further episodes of cerebrovascular accidents. In one patient, transient ischemic attack (focal neurologic deficit without a corresponding lesion on computed tomographic scan) was suspected. In this patient transesophageal echo contrast study demonstrated residual right-to-left shunt. Surgical closure of the residual defect was performed at the discretion of the primary cardiologist. This patient was included in the event-free survival curve depicted in Fig. 7. Transesophageal contrast study with Valsava was performed in seven other patients 6 months after device implantation. No residual rightto-left shunt was observed in these patients. No episodes of endocarditis or thrombus formation (by means of patient history and by two-dimensional echographic scans of the device and atrial septum) on the device were observed in any patient.

Twenty patients underwent surgery (14 device dislodgements, 3 residual shunts and/or atrial perforation, 2 device inspections for wire distortion, and 1 paradoxic embolism) a few hours to 9 months after device implantation (Fig. 4). Surgery was uneventful in all these patients. Follow-up 3 months to 3 years after surgery was available in 16 patients. All were without symptoms and significant cardiovascular abnormality.

\section{COMMENTS}

Buttoned device for atrial septal defect occlusion. The first atrial septal defect occlusion by the buttoned device was performed in September 1988. Nine implantations were performed with the first-generation device; most have been described elsewhere. ${ }^{14-17}$ The major problems with the first-generation device were inability to recognize adequate buttoning and difficulty in withdrawal of nonimplanted devices. Modifications of the retrieval system made percutaneous retrieval of nonimplanted devices possible. Indeed, all nonimplanted second-generation devices were extracted transvenously. Moreover, the following improvements were made to the method. (1) Withdrawing a balloon catheter under fluoroscopy and color flow-mapping improved the method of sizing the defect. Multiple or irregular defects could therefore be assessed by this technique. (2) Tables with the optimal device selection for each defect size were established (Table V). (3) Good quality fluoroscopy and echocardiography with color flow mapping were used to guide the device. Fluoroscopy should be 

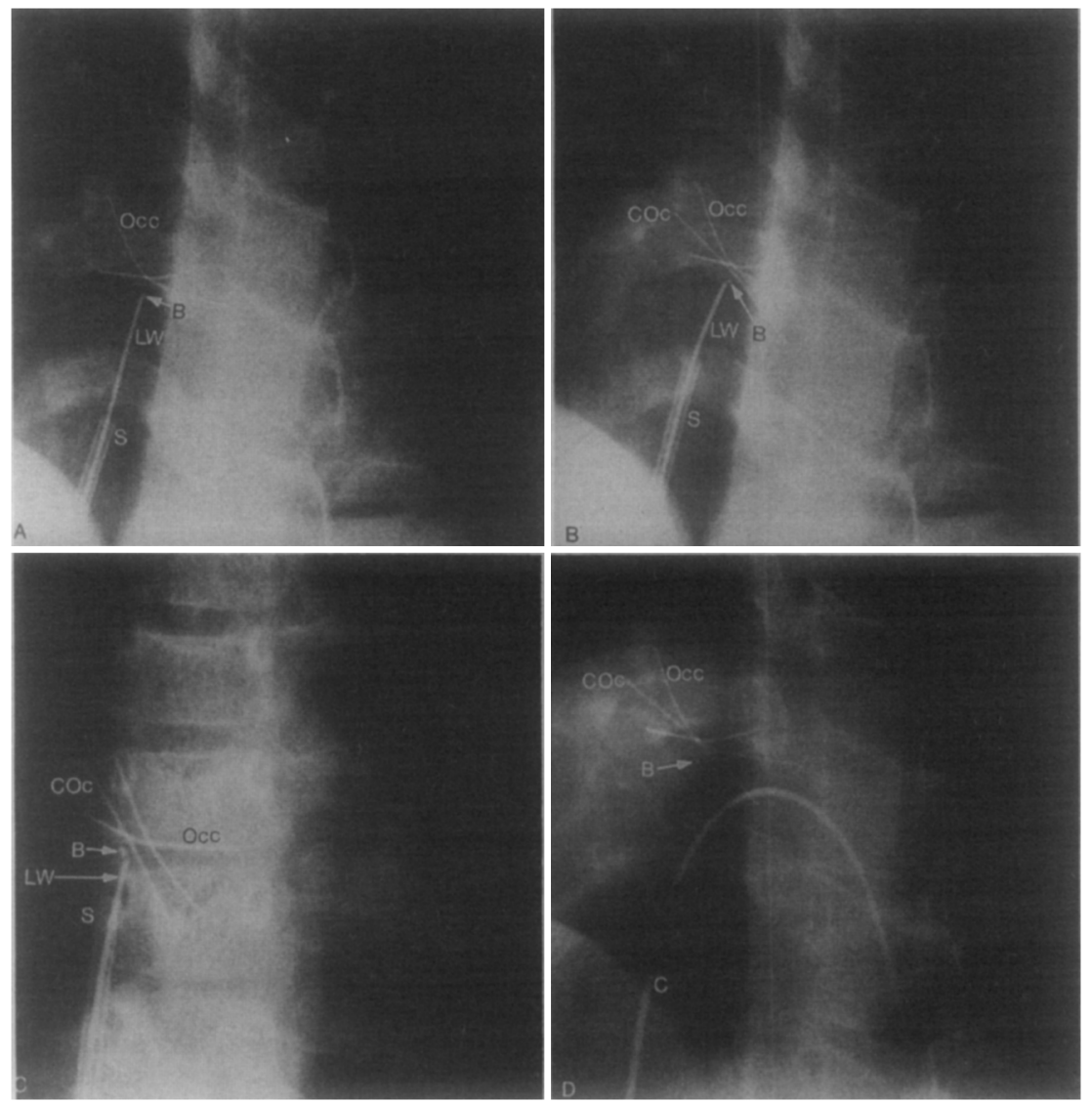

Fig. 10. Selected cineradiographic frames of device during and after implantation of device across atrial septal defect. A, Occluder $(O c c)$ is delivered into left atrium. Four-chamber view of heart is shown. Radiopaque marker on "button" $(B)$, loading wire $(L W)$, and sheath $(S)$ through which occluder had been delivered are shown. B, Counter-occluder $(C O c)$ is delivered into right atrium past button. Loading wire and sheath are also shown. C, Anteroposterior view of B. D, Device is disconnected from wire. Occluder, counteroccluder, and button are shown in four-chamber view. Catheter $(C)$ is in right ventricle.

Table V. Stretched atrial septal defect sizes and recommended device sizes

\begin{tabular}{lc}
\hline $\begin{array}{c}\text { Stretched atrial } \\
\text { septal defect } \\
\text { diameter }(\mathrm{mm})\end{array}$ & $\begin{array}{c}\text { Recommended } \\
\text { device size }(\mathrm{mm})\end{array}$ \\
\hline$\leq 10$ & 25 \\
$11-12$ & 30 \\
$13-15$ & 35 \\
$16-20$ & 40 \\
$21-23$ & 45 \\
$24-25$ & 50 \\
\hline
\end{tabular}

sensitive enough to demonstrate the skeleton wires, radiopaque button, and catheters and sheaths used (Fig. 10). Good quality echocardiography and color flow mapping can be achieved by means of the transthoracic approach in small children, but the transesophageal approach is preferable in older children and adults. (4) The investigators were instructed to manipulate the occluder in the left atrium to achieve effective occlusion, alignment with the atrial septum, and noninterference with other structures.

Residual shunts. The significance of the relatively high incidence of trivial residual shunts by color flow mapping immediately after implantation is not known but is not alarming because (1) there was no clinical evidence of a shunt (no murmurs, a normally moving second heart sound); (2) right ventricular volume overload by echocardiography improved; (3) there is experimental data that the device is well-endothelialized if properly positioned on the atrial septum $^{6-8,22}$; (4) there is evidence in our data from the FDA trial ${ }^{18}$ and with the clamshell device ${ }^{23}$ that most of the initial trivial shunts tend to become smaller or disappear.

Indications. The major indication for the buttoned device atrial septal defect occlusion was management 
of left-to-right shunts. However, a few patients with small right-to-left shunts or previous strokes also had successful occlusions. Because the occluder of this device is on the left atrial side, it is reasonable to assume that this device should not be used for large right-to-left shunts. Indeed, in one case ( 1 of 20 in which the implanted device was not left in) of significant right-to-left shunt the device had to be withdrawn because it increased the magnitude of the right-to-left shunt. A double-disc or an inverted-disc device already tested in animals is expected to address this problem (Sideris EB, Rao PS; unpublished observations).

Echocardiographic assessment. Presence of good septal margin in several views (Fig. 1) is necessary for proper placement of the device. Patients with small septal rims are unlikely to have successful transcatheter occlusion of their atrial defects. In this study we used only such subjective criteria and did not prospectively make any measurements to solve this problem. Comparing the septal margins and margin/ atrial septal defect ratio between groups of patients that had successful versus unsuccessful implantation of the device in future studies may help resolve this issue.

Complications. The complications reported herein reflect the learning curve of the method. Indeed, this is the cumulative experience of 16 investigators/centers. Most investigators underwent animal implantation training and were instructed in their first cases, but most required more independent experience. Unbuttoning, the most common complication occurred in $13(7 \%)$ of 180 cases. In 12 of 13 cases, unbuttoning occurred with investigators just starting with the method, probably as a result of their hesitation to pull the occluder strongly and stretch the button loop when they were pushing the counteroccluder. Although there are several radiographic signs of good buttoning and the device can be retrieved before release, imperfections of the guidance system made this assessment inaccurate on some occasions.

Although the unbuttoning complication does not frequently occur with experienced investigators, minor modifications of the button loop were thought to be necessary to facilitate buttoning. A second small loop that keeps the radiopaque button straight with minor traction was introduced (Fig. 2). After this modification 65 device implantations were performed with only two unbuttonings.

Most of the unbuttoned occluders (11 of 13) remained on the left atrial side of the atrial septum, well occluding the defect. In one case the device was totally embolized into the pulmonary artery after re- lease, most likely because of selection of too small an occluder, probably because of inadequate balloon sizing. All patients remained hemodynamically stable after unbuttoning/embolization, and the surgical correction of the defect and removal of the device were undertaken at the same time.

Nevertheless, $160(89 \%)$ of 180 patients with an implanted device (or 160 [80\%] of 200 patients with intent to close the defect) remained free of further intervention; their defects were well occluded. This success rate is expected to improve in the future. So far, the worst complication of the method is the need for surgery in nearly $11 \%$ of patients in whom the device was implanted. The need for surgical intervention was usually related to unbuttoning, and this problem appears to have been improved by the third-generation device. Consequently, the risk of unbuttoning is likely to be reduced, and therefore the requirement for surgical intervention may diminish.

Comparison with other devices. The only other device that has undergone clinical trials comparable to the buttoned device is the Bard Clamshell Septal Occluder (USCI). Preliminary results ${ }^{24}$ and a summary of the first 100 cases $^{25}$ have been reported. Of the first 40 patients with intent to close, ${ }^{24} 34(85 \%)$ underwent device implantation. Device embolization was noted in $2(6 \%)$ of 34 patients. Residual shunts, evaluated in 19 patients 6.5 months after implantation, were present in $\left.7(37)_{1}\right)$. Of the first 100 patients ${ }^{25}$ with intent to occlude the atrial septal defect, $93(93 \%)$ had the device implanted. Only 3 $(3.2 \%)$ device embolizations were reported. ${ }^{25}$ Complete closure by echo Doppler was stated to be in the range of $84 \%$ of the patients. These results are similar to those reported in this article on the buttoned device. However, the Bard Clamshell Occluder requires an $11 \mathrm{~F}$ sheath for delivery in contrast to the buttoned device, which requires an $8 \mathrm{~F}$ (9F for larger devices) sheath. In addition, an incidence of late fractures of one or more arms of the Clamshell device of approximately $30 \%$ with embolization 20,21 has prompted the investigators to withdraw the device from clinical trials.

Limitations. Although we are reasonably sure that our conclusions are valid, there are certain limitations to this study. The multiinstitutional nature of the study, by necessity, introduces some known and some unknown variables in the selection of patients and method of closure. In addition, the learning curve of the new investigators also adds to the problem.

Unfortunately, only a certain percentage of patients with atrial septal defect are candidates for this method. Ostium primum defects, sinus venosus de- 
fects, and secundum defects $>25 \mathrm{~mm}$ could not be closed. Furthermore, a small number of patients with defects $<25 \mathrm{~mm}$ could not be occluded because of a small left atrium, short septal length, lack of supportive tissue, or unusual location of the defect. One possibly remediable factor could be the ability of the operator to manipulate the device properly in a nonideal defect. It is likely that more than half of all secundum atrial septal defects are suitable for transcatheter closure. Improvement of this method and the evolution of other transcatheter methods are expected to improve the current management of patients with cardiac defects.

Conclusions. Buttoned devices were used to occlude secundum atrial septal defects in 180 patients. Device dislodgment $(7.8 \%$ ) was the major complication of this procedure. Although dislodgment required transcatheter or surgical retrieval, the patients were hemodynamically stable and underwent successful surgical correction. With increasing operator experience and some improvement of the device design (third-generation), the unbuttoning complication is likely to be reduced. The data we present suggest that transcatheter occlusion of the secundum atrial septal defect is feasible, relatively safe, and effective in most cases. Transcatheter occlusion with the buttoned device appears to be a viable alternative to surgery for some patients with secundum atrial septal defect.

\section{SUMMARY}

Several devices are available for transcatheter occlusion of atrial septal defect. This report describes the international experience with the buttoned device. During a 4.5-year period ending in February 1993, 180 transcatheter atrial septal defect occlusions were performed with the buttoned device. Patient age varied between 0.6 and 76 years and stretched atrial defect diameter between 5 and $25 \mathrm{~mm}$. The defects were closed with 25 to $50 \mathrm{~mm}$ devices delivered through $8 \mathrm{~F}$ (148 patients) or $9 \mathrm{~F}$ (32 patients) sheaths. Twelve patients were adults whose defects were closed to prevent recurrence of cerebrovascular accidents caused by presumed paradoxic embolism. In the remaining patients the atrial defect was closed to treat the left-to-right shunt. The atrial septal defects were effectively occluded as demonstrated by (1) decrease in pulmonary-to-systemic flow ratio from $2.1 \pm 0.6$ (mean $\pm \mathrm{SD})$ to $1.05 \pm 0.1(p<0.01)$ by oximetry; (2) normalized $S_{2}$ and disappearance of the diastolic murmur by auscultation; and (3) improvement in right ventricular volume overloading by echocardiogram. However, trivial to small shunts could be detected by color Doppler studies in 76
(45\%) of 168 patients in whom such data are available. Complications included unbuttoning in 13 and whole-device embolization in 1 . All patients remained stable, and retrieval of the device and surgical closure of the atrial septal defect were accomplished in 10 patients. Transcatheter retrieval was used in the remaining 4 patients. The incidence of unbuttoning, a major complication of the procedure, appeared to decrease with the increasing experience of the investigators and with device modification (third-generation). The follow-up duration varied between 1 month and 4 years. Six patients required surgery during the follow-up period. In the remaining patients $(n=160)$, clinical examination did not reveal signs of atrial shunts. Color Doppler studies revealed either complete disappearance of the previously demonstrated shunts or further diminution of their size. The results indicate that transcatheter occlusion of the atrial septal defects with buttoned devices is feasible, relatively safe, and effective, and it appears to be a viable alternative to surgery for some patients with secundum atrial septal defect. Complications are infrequent and should improve with experience.

We thank Drs. R. Arora, I. H. Attia, P. S. Chopra, D. J. Ende, G. K. Gupta, V. K. Gupta, 7. Lababidi, J. Losay, R. Lochan, R. Mocellin, A. D. Wilson, and R. Zamora for their contribution to the clinical material; R. Koscik for her advice and assistance in the statistical analysis reported in this paper; and N. Kelsey and $M$. Kraak for their assistance in the preparation of this manuscript.

\section{REFERENCES}

1. King TD, Mills NL. Nonoperative closure of atrial septal defects. Surgery $1974 ; 75: 383-8$.

2. Mills NL, King TD. Nonoperative closure of left-to-right shunts. J Thorac Cardiovasc Surg 1976;72:371-8.

3. King TD, Thompson SL, Steiner C, Mills NL. Secundum atrial septal defect: nonoperative closure during cardiac catheterization. JAMA 1976;235:2506-9.

4. Rashkind WJ. Experimental transvenous closure of atrial and ventricular septal defects [Abstract]. Circulation 1975;52:11-8.

5. Rashkind WJ, Cuaso CC. Transcatheter closure of atrial septal defects in children [Abstract]. Eur J Cardiol 1977;8:119-20.

6. Rashkind WJ. Transcatheter treatment of congenital heart disease. Circulation 1983;67:711-6.

7. Lock JE, Rome JJ, Davis R, Van Praagh S, Perry SB, Van Praagh R, Keane JF. Transcatheter closure of atrial septal defects: experimental studies. Circulation 1989;79:1091-9.

8. Sideris EB, Sideris SE, Fowlkes JP, Ehly RL, Smith JE, Gude RE Transvenous atrial septal occlusion in piglets using a "buttoned" double-disc device. Circulation 1990;81:312-8.

9. Fyler DC. Atrial septal defect secundum. In: Fyler DC, ed. Nadas' pediatric cardiology. Philadelphia: Hanley and Belfus, 1992:513-24.

10. King TD, Thompson SL, Steiner C, Mills NL. Measurement of atrial septal defect during cardiac catheterization: experimental and clinical trials. Am J Cardiol 1978;41:537-42

11. Forfar JC, Godman MJ. Functional and anatomical correlates in atria septal defect: an echocardiographic study. Br Heart J 1985;54:193-200.

12. Rao PS, Langhough R. Relationship of echographic, shunt flow, and angiographic size to the stretched diameter of the atrial septal defect. AM HEART J 1991;122:505-8.

13. Rao PS, Langhough R, Boekman RH, Lloyd TR, Sideris EB. Echocar- 
diographic estimation of balloon-stretched diameter of secundum atrial septal defects for transcatheter occlusion. AM HEART J 1992;124:172-5.

14. Rao PS, Wilson AD, Levy JM, Gupta VK, Chopra PS. Role of "buttoned" double-disc device in the management of atrial septal defects. AM HEaRT J 1992;123:191-200.

15. Sideris EB, Sideris SE, Thanopoulos BD, Ehly RL, Fowlkes JP. Transvenous atrial septal defect occlusion by the "buttoned" device. Am J Cardiol 1990;66:1524-6.

16. Rao PS, Wilson AD, Chopra PS. Transcatheter closure of atrial septal defects by "buttoned" devices. Am J Cardiol 1992;69:1056-61.

17. Rao PS, Sideris EB, Chopra PS. Catheter closure of atrial septal defect: successful use in a $3.6 \mathrm{~kg}$ infant. AM HEART J 1991;121:1826-9.

18. Lloyd TR, Rao PS, Beekman RH III, Mendelsohn AM, Sideris EB. Atrial septal defect occlusion with the buttoned device: a multi-institutional U. S. trial. Am J Cardiol 1994;73:286-91.

19. Arabia FA, Rosado LJ, Lloyd TR, Sethi GK. Management of complications of Sideris transcatheter devices for atrial septal defect closure. J Thorac Cardiovasc Surg 1993;106:886-8.
20. Latson LA, Benson LN, Hellenbrand WE, Mullins CE, Lock JE. Transcatheter closure of ASD-early results of multicenter trial of the Bard clamshell septal occluder [Abstract]. Circulation 1991;84(suppl II):544

21. Bridges ND, Hellenbrand W, Latson L, Filiano J, Newburger NW. Lock JE. Transcatheter closure of patent foramen ovale after presumed paradoxical embolism. Circulation 1992;86:1902-8.

22. Beekman RH, Rocchini AP, Snider AR, Rosenthal A. Transcatheter atrial septal defect closure: preliminary experience with the Rashkind occluder device. J Intervent Cardiol 1989;2:33-41.

23. Boutin C, Musewe NN, Smallhorn JF, Dyek JD, Kobayashi T, Benson LN. Echocardiographic follow-up of atrial septal defect after catheter closure by double-umbrella device. Circulation 1993:88:621-7.

24. Rome JJ, Keane JF, Perry SB, Spevak PJ, Lock JE. Double-urnbrella closure of atrial defects: initial clinical applications. Circulation 1990;82:751-8

25. Latson LA. Transcatheter closure of atrial septal defects. In: Rao PS, ed. Transcatheter therapy in pediatric cardiology New York: Wiley Liss, 1993:335-48. 